\title{
MODELING LAMINAR HEAT TRANSFER IN A CURVED RECTANGULAR DUCT WITH A COMPUTATIONAL FLUID DYNAMICS CODE
}

\author{
Jorge Facão and Armando C. Oliveira \\ Department of Mechanical Engineering and Industrial Management, \\ University of Porto, Porto, Portugal
}

Flow and convective heat transfer in a curved rectangular channel was modeled and the heat transfer coefficient assessed, using the FLUENT code. The conditions considered are representative of an application to solar collectors with heat pipes. A wide range of Reynolds and Dean numbers was considered, under laminar flow conditions. Results show that the Nusselt number for the curved duct is up to 10 times higher than for a straight duct, due to counterrotating secondary vortices formation. The flow pattern changes from one pair of vortices to three pairs, for a Dean number of 131. Above a Dean number of 1,200, the contours of secondary flow streamlines are similar and the variation in Nusselt number is small.

\section{INTRODUCTION}

Curved channels are widely used in thermal engineering applications. One example is the use of such channels in the condenser area of heat pipe solar collectors, [1-3]. The curved shape allows contact between the curved channel inner surface and the heat pipe. This facilitates heat transfer between the heat pipe condenser and the fluid to be heated (usually water). Figure 1 represents the condenser region of a heat pipe solar collector.

In spite of being commonly used, this geometry has not been adequately quantified in terms of heat transfer characteristics.

The most prominent characteristic of flows in curved ducts is the secondary flow induced by centrifugal forces due to the curvature of the duct. These centrifugal forces lead to the development of a lateral pressure gradient and the appearance of counterrotating secondary vortices. The heat transfer rate is higher than in straight ducts, which contributes to a wide dissemination in engineering applications.

Received 13 May 2004; accepted 25 January 2005.

The authors wish to thank Fundação para a Ciência e a Tecnologia (P), for the scholarship of the first author. They also wish to express their gratitude to the European Commission (DG Research) for partially funding the work done, under the Hybrid-CHP research project (contract ENK5-CT-200000080). The other partners of the project are also acknowledged.

Address correspondence to Armando C. Oliveira, Department of Mechanical Engineering and Industrial Management, Faculty of Engineering, University of Porto, Rua Dr. Roberto Frias, 4200-465 Porto, Portugal. E-mail: acoliv@fe.up.pt 


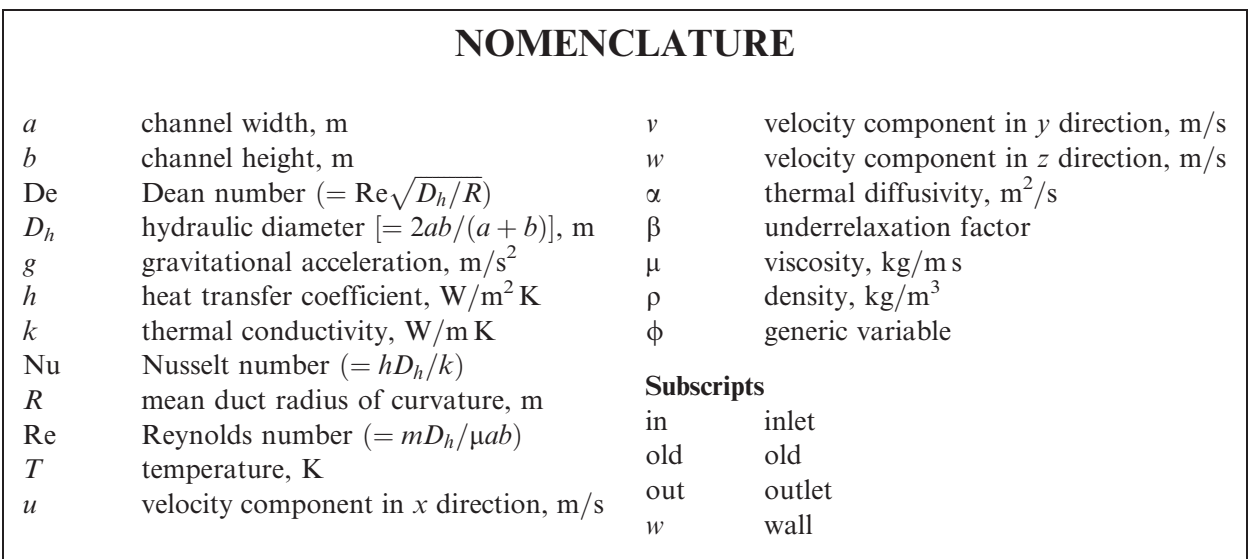

Dean $[4,5]$ did an earlier theoretical work on fluid motion in a curved pipe using a perturbation technique. He predicted the characteristics of the twin-vortex secondary flow and pointed out that the dynamic similarity of such a flow depends on a dimensionless parameter, De, called the Dean number, which is defined by $\mathrm{De}=\operatorname{Re} \sqrt{D_{h} / R}$. The Dean number characterizes the intensity of the cross-stream flow driven by an imbalance between centrifugal and radial pressure-gradientinduced forces. The perturbation technique is very tedious and the solution quickly diverges with increase in Dean number.

Mori et al. [6] presented analytical and experimental results for fully developed laminar flow in a curved square channel under constant wall heat flux, using a boundary-layer approximation. Their results are applicable only for large Dean numbers. Ratios of curved-duct Nusselt number to straight-duct Nusselt number ranged from 2.3 to 4.1 .

Cheng and Akiyama [7] made the first numerical study of laminar forcedconvection heat transfer in curved rectangular ducts. The method was the point successive overrelaxation method under the thermal boundary conditions of axially

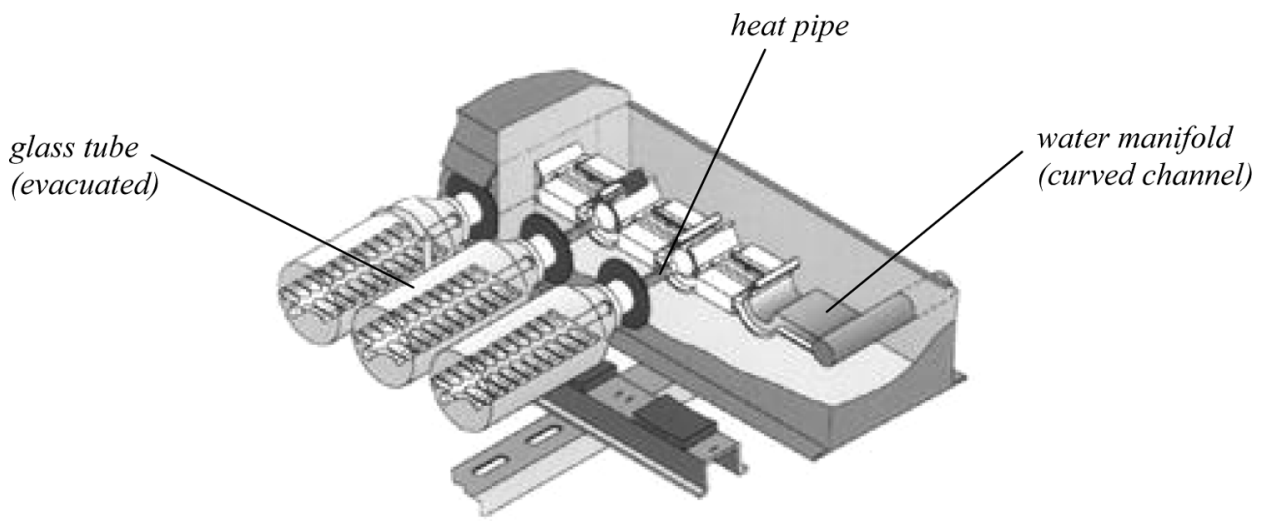

Figure 1. Condenser region of a heat pipe solar collector [3]. 
uniform wall heat flux and peripherally uniform wall temperature at any axial position. The limitation of the numerical method was encountered at a reasonably high Dean number (approx. 200). Graphical results for the ratio of Nusselt number to straight Nusselt number versus Dean number were presented for aspect ratios of $0.2,0.5,1,2$, and 5 and a Prandtl number of 0.73 . For a square channel (aspect ratio equal to 1), the effect of Prandlt number was also investigated.

Chilukuri and Humphrey [8] studied numerically a curved square duct using a finite-difference method for the steady state, incompressible laminar flow of a constant-physical-properties fluid, for which the Boussinesq approximation applies. They determined the influence of buoyant forces. The boundary condition was constant temperature at all walls in the curved duct. The Nusselt number for the curved square duct ranged from 14 to 16 .

Hwang and Chao [9] studied laminar convection in a curved isothermal square duct with a finite-difference implicit-scheme approximation. The range of Nusselt number was 2.976 to 29.012 for $0<\mathrm{De}<1,000$, a Prandtl number of 7 , and a large ratio of $R / D_{h}$. The flow pattern depends on Dean number: For De $<114$ the flow has two vortices, and for De $>143$ the pattern has four vortices. For $114<$ De $<143$ the flow pattern depends on the initial flow pattern used. Winters [10] showed that the transition of the two-vortices to four-vortices flow patterns happens for a Dean number between 113 and 191. The development of two pairs of Dean vortices can be explained by comparing this geometry with a boundary-layer flow over a concave wall - the Görtler problem. In the Görtler problem the flow in the boundary layer is centrifugally unstable, which causes a transition to streamwise, counterrotating Görtler vortices in the boundary layer. Because of the unbound nature of the flow, Görtler vortices develop continuously in the streamwise direction until the flow breaks down into turbulence [11]. It is believed that the mechanism that causes Dean and Görtler vortices is the same [12].

Chung and Hyunn [13] presented a numerical study of a laminar flow in $90^{\circ}$ curved square ducts over wide ranges of Reynolds numbers (and corresponding Dean numbers), with constant temperature and constant heat flux at all walls in the curved region. They concluded that the Nusselt number in the duct inlet region is higher on the convex wall than on the concave wall. However, at intermediate and far downstream locations, heat transfer is more effective on the concave wall.

Ligrani et al. [14] presented an experimental study on heat transfer in a curved rectangular duct with an aspect ratio of 40 over a range of Dean numbers from 100 to 300 . The boundary conditions were uniform heat flux at the channel walls. For a Dean number of 300, the maximum local Nusselt number on the concave surface was 13, versus 8 on the convex surface. In a later work [15], they extended the study to turbulent flow.

Chandratilleke and Nursubyakto [16] presented a numerical simulation of flow through a curved rectangular duct heated on the concave wall with a constant heat flux, with aspect ratios from 1 to 8 and Dean numbers lying in the range of 20 to 500 . The governing equations were transformed into vorticity-streamfunction form and solved using a finite-volume method. The number of Dean vortices was influenced by the duct aspect ratio. A duct with an aspect ratio of 8 yields three pairs of vortices. The Nusselt number for an aspect ratio of 8 was in the range of 7 to 11.5 , for a Dean number from 20 to 500. Chandratilleke and Nursubyakto concluded that the Nusselt number for a curved duct is $20-70 \%$ higher than for a straight duct. 


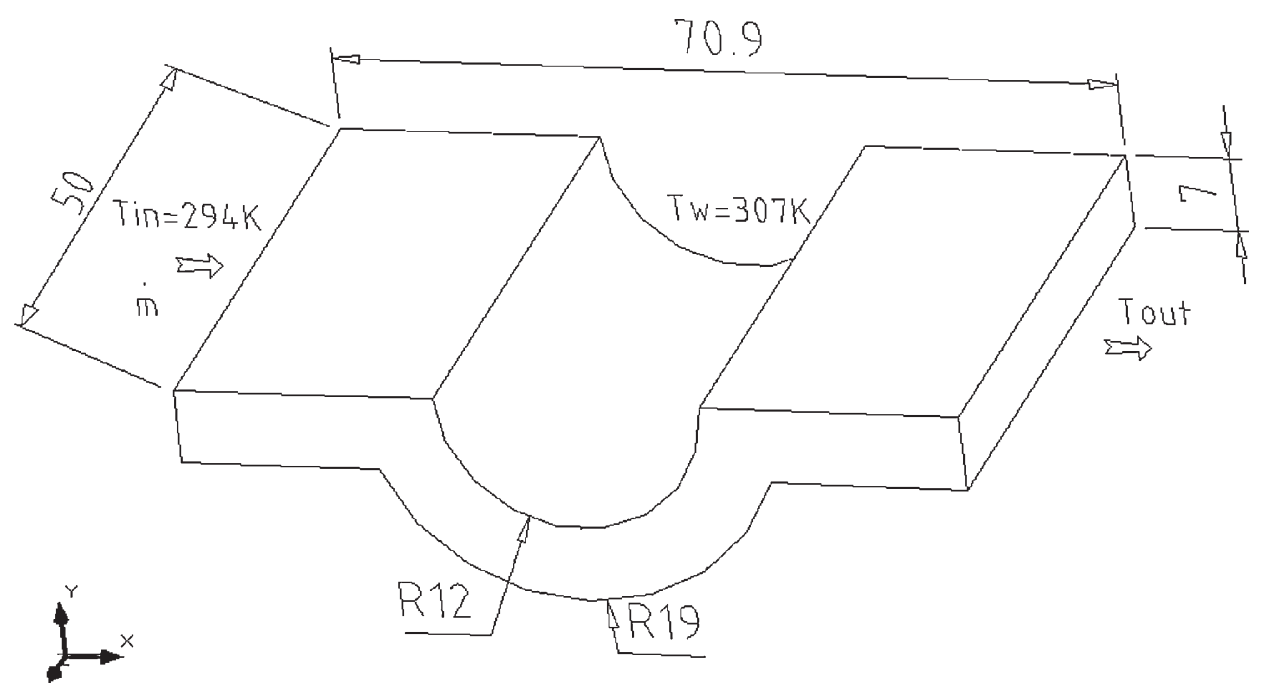

Figure 2. Duct geometry (dimensions in $\mathrm{mm}$ ).

Several other studies have been done on curved-shape channels, although with different characteristics, operating, or boundary conditions [17-26]. Zhang et al. [17] studied the effect of combined radiation and forced convection in the entrance of a curved heat pipe. Dong and Ebadian [18] investigated thermal developing flow in a curved duct but with an elliptical section, and the effects of buoyancy [19]. Sturgis and Mudawar $[20,21]$ studied critical heat flux for boiling in a curved rectangular channel. Wang and Yang [22] performed a numerical analysis of forced convection, but for curved square channels. Gyves and Irvine [23, 24] made a numerical comparison of laminar forced convection in curved rectangular and square channels. They also quantified the effect of buoyancy. However, the maximum Dean number considered was equal to 210. Andrade and Zaparoli did an analysis of the effect of temperature-dependent viscosity [25], while Velidandla et al. performed measurements of turbulent velocities in channels with curved walls [26].

In this article, the laminar flow for a rectangular curved duct with an aspect ratio of 7.14 is simulated numerically over a wide range of Dean numbers, using the three-dimensional version of a commercial computational fluid dynamics code: FLUENT [27] (control-volume method). The duct corresponds to an application to the condenser section of a heat pipe solar collector. The convex wall is heated at constant temperature (approximation) and the other walls are insulated. Figure 2 represents the duct geometry. The conditions are representative of those in a prototype heat pipe solar collector [1].

\section{SIMULATION CONDITIONS}

Table 1 shows the boundary conditions used in the simulation. The inlet temperature is $294 \mathrm{~K}$ and the wall temperature is $307 \mathrm{~K}$, values that are in agreement with average values obtained during solar collector experimental testing. Convective 
Table 1. Boundary conditions used in the simulations

\begin{tabular}{lc}
\hline Inlet & $T=294 \mathrm{~K}$ \\
Outlet & $P=0 \mathrm{~Pa}$ \\
Convex surface & $T=307 \mathrm{~K}$ \\
Other surfaces & Adiabatic \\
\hline
\end{tabular}

heat transfer occurs in the convex surface of the duct. Forced convection has a dominant role in heat transfer: The ratio between the Grashof number and the square of the Reynolds number is much smaller than unity $(<5 \mathrm{E}-4)$, and thus the effect of natural convection can be ignored.

Due to the presence of lateral vortices, the flow is simulated in three dimensions. The conservation equations (continuity, momentum, and energy) for Newtonian incompressible steady flow can be written as follows.

Continuity equation:

$$
\frac{\partial u}{\partial x}+\frac{\partial v}{\partial y}+\frac{\partial w}{\partial z}=0
$$

Momentum equation in $x$ direction:

$$
\rho\left(u \frac{\partial u}{\partial x}+v \frac{\partial u}{\partial y}+w \frac{\partial u}{\partial z}\right)=-\frac{\partial P}{\partial x}+\mu\left(\frac{\partial^{2} u}{\partial x^{2}}+\frac{\partial^{2} u}{\partial y^{2}}+\frac{\partial^{2} u}{\partial z^{2}}\right)
$$

Momentum equation in $y$ direction:

$$
\rho\left(u \frac{\partial v}{\partial x}+v \frac{\partial v}{\partial y}+w \frac{\partial v}{\partial z}\right)=-\frac{\partial P}{\partial y}+\rho g_{y}+\mu\left(\frac{\partial^{2} v}{\partial x^{2}}+\frac{\partial^{2} v}{\partial y^{2}}+\frac{\partial^{2} v}{\partial z^{2}}\right)
$$

Momentum equation in $z$ direction:

$$
\rho\left(u \frac{\partial w}{\partial x}+v \frac{\partial w}{\partial y}+w \frac{\partial w}{\partial z}\right)=-\frac{\partial P}{\partial z}+\rho g_{z}+\mu\left(\frac{\partial^{2} w}{\partial x^{2}}+\frac{\partial^{2} w}{\partial y^{2}}+\frac{\partial^{2} w}{\partial z^{2}}\right)
$$

Table 2. Influence of the number of cells on heat transfer coefficient $(\mathrm{De}=1,494)$

\begin{tabular}{lcc}
\hline Number of hexahedral cells & $h\left(\mathrm{~W} / \mathrm{m}^{2} \mathrm{~K}\right)$ & $\mathrm{Nu}$ \\
\hline 21,500 & 737 & 15.4 \\
73,650 & 1,156 & 24.1 \\
184,000 & 1,505 & 31.5 \\
298,000 & 1,535 & 32.1 \\
735,000 & 1,779 & 37.1 \\
833,000 & 1,808 & 37.8 \\
\hline
\end{tabular}




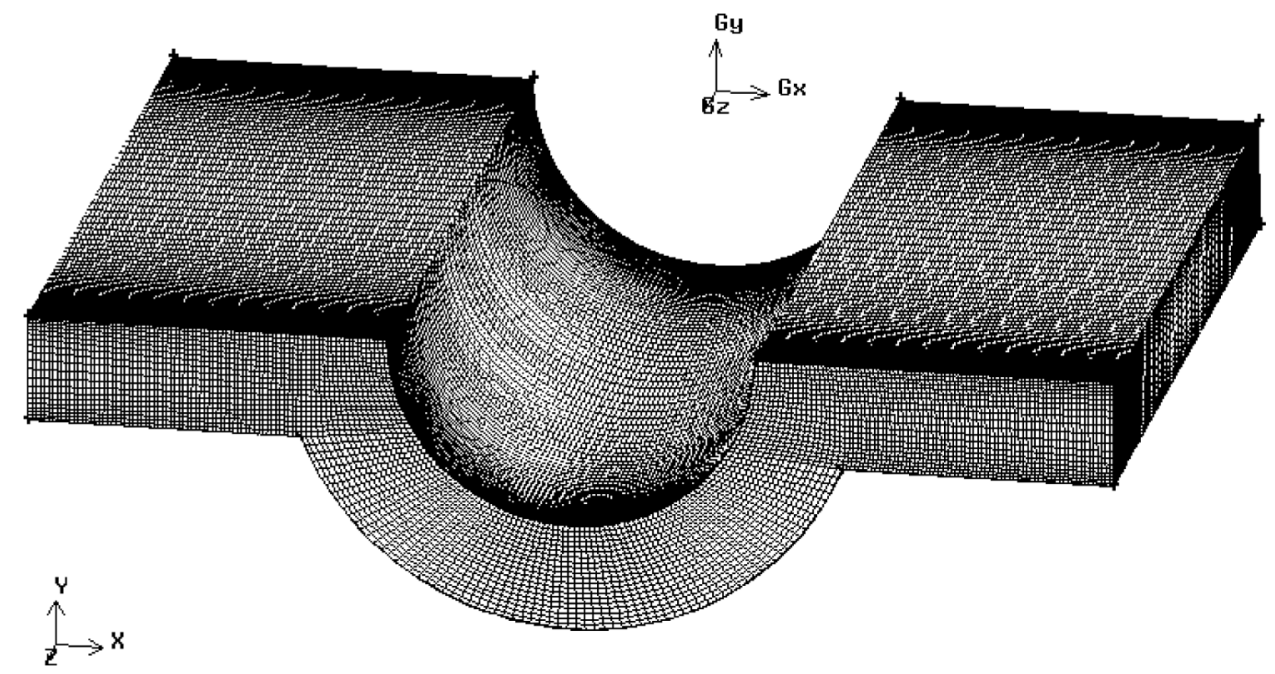

Figure 3. Mesh for a geometric model with 833,000 hexahedral cells.

Energy equation (viscous-dissipation term negligible):

$$
u \frac{\partial T}{\partial x}+v \frac{\partial T}{\partial y}+w \frac{\partial T}{\partial z}=\alpha\left(\frac{\partial^{2} T}{\partial x^{2}}+\frac{\partial^{2} T}{\partial y^{2}}+\frac{\partial^{2} T}{\partial z^{2}}\right)
$$

These equations were discretized and solved with the finite-volume method [28]. The pressure was coupled to velocity with the SIMPLE algorithm (SemiImplicit Method for Pressure-Linked Equations), which was developed by Patankar and Spalding [29].

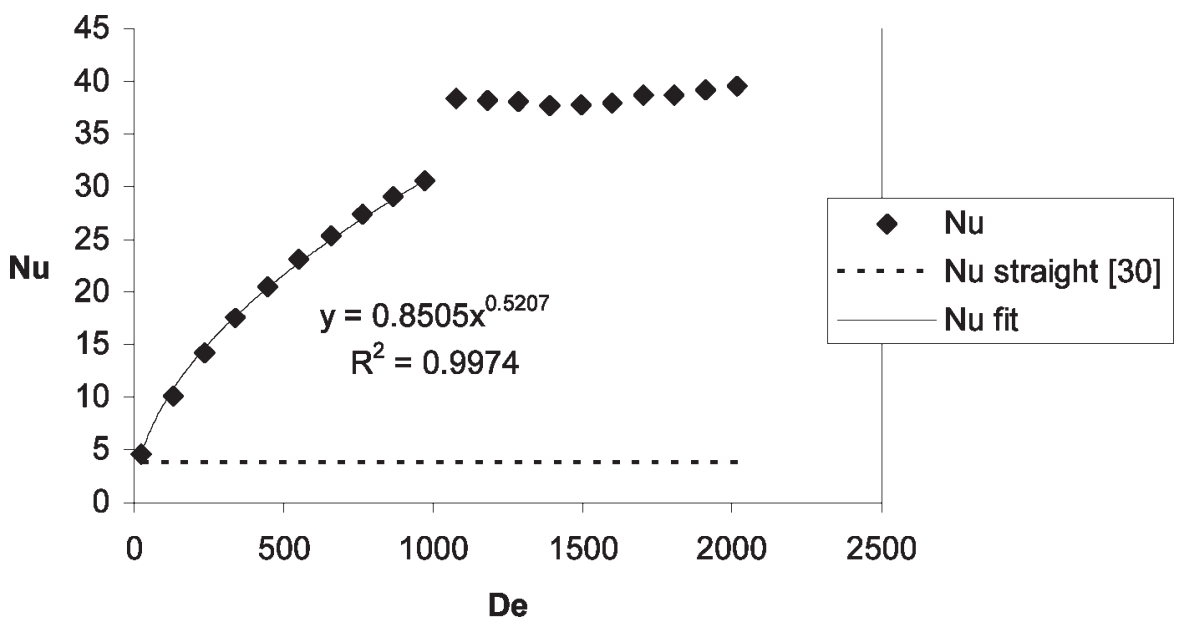

Figure 4. Variation of Nusselt number with Dean number. 
Table 2 presents the convective heat transfer coefficients for models with various numbers of hexahedral cells. The coefficient increases with the number of hexahedral cells, but the augmentation is more important for the first three changes. This is due to the possibility of simulating the vortices in models with more hexahedral cells. The model used in further simulations was the model with 833,000 hexahedral cells.

Figure 3 shows the mesh for a geometric model with 833,000 hexahedral cells. The mesh is tighter near the walls, to account for boundary-layer generation.
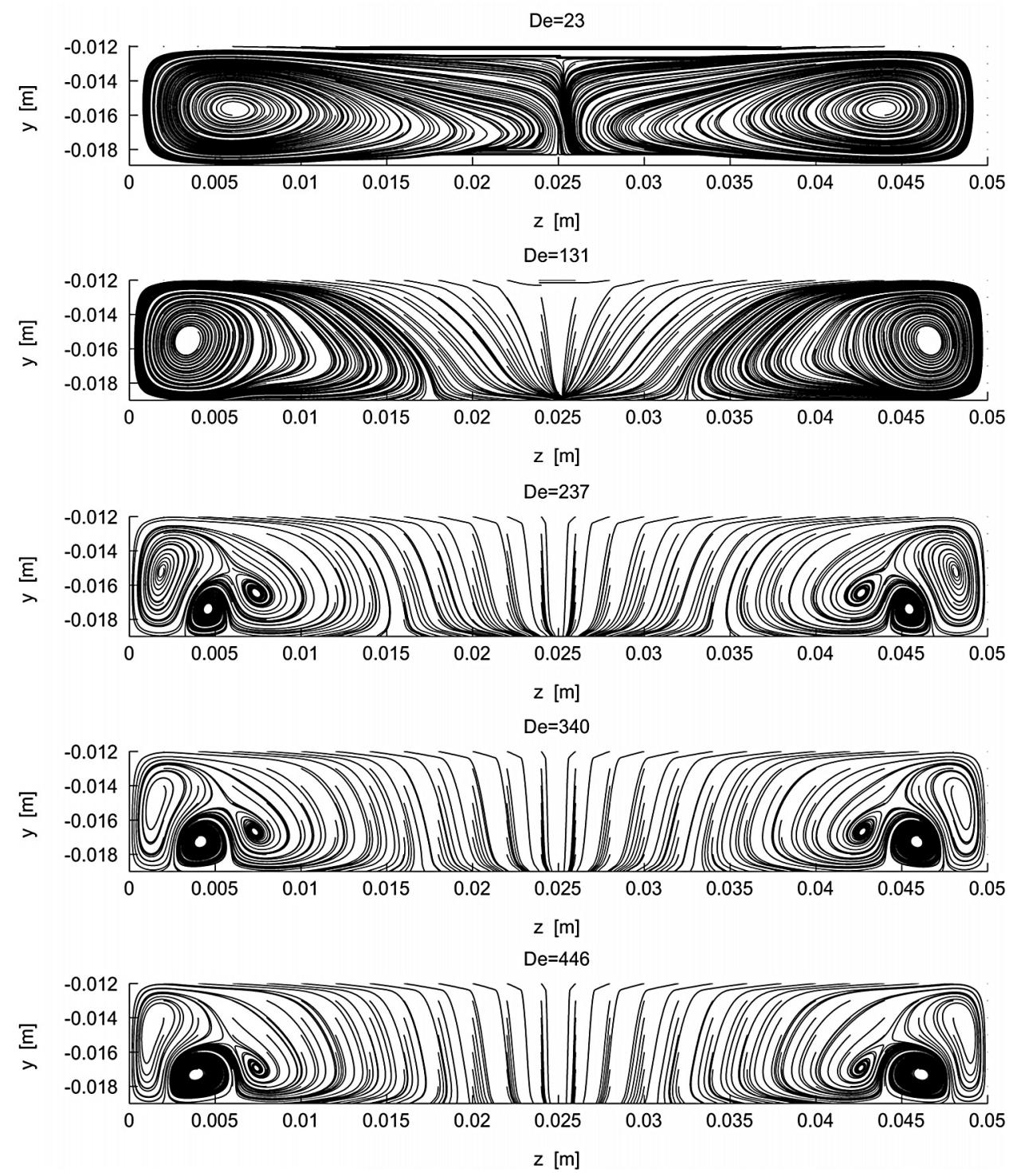

Figure 5. Flow pattern in the middle of the duct for $23 \leq \mathrm{De} \leq 446$. 

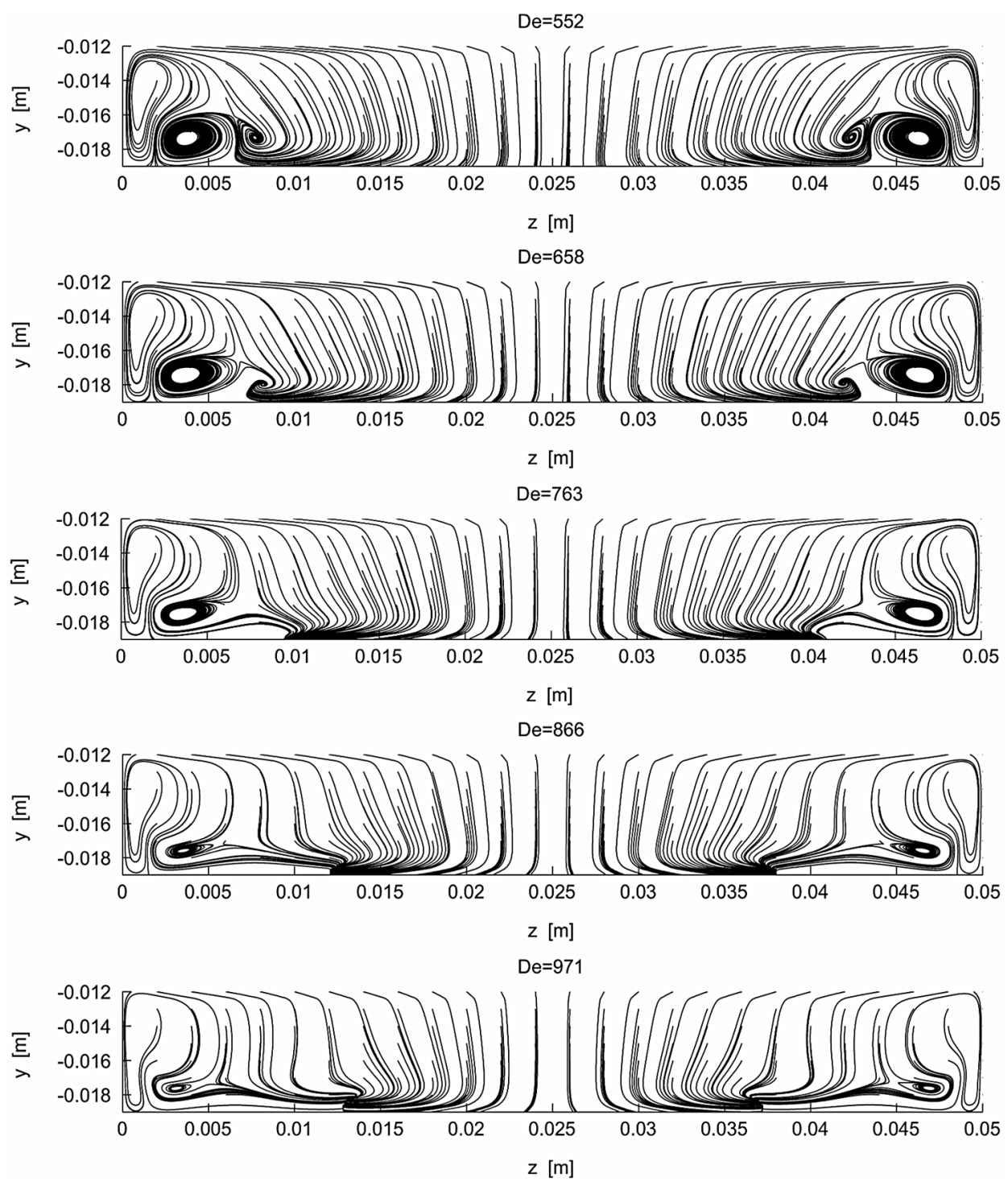

Figure 6. Flow pattern in the middle of the duct for $552 \leq$ De $\leq 971$.

The convergence is faster for smaller flow rates. For large flow rates the momentum relaxation factor, $\beta$ in Eq. (6), was decreased to allow convergence:

$$
\phi=\phi_{\text {old }}+\beta \Delta \phi
$$

\section{RESULTS AND DISCUSSION}

Heat transfer in the convex surface has been calculated over the range of the laminar regime $(26<\operatorname{Re}<2,265)$. Figure 4 presents the Nusselt number as a 

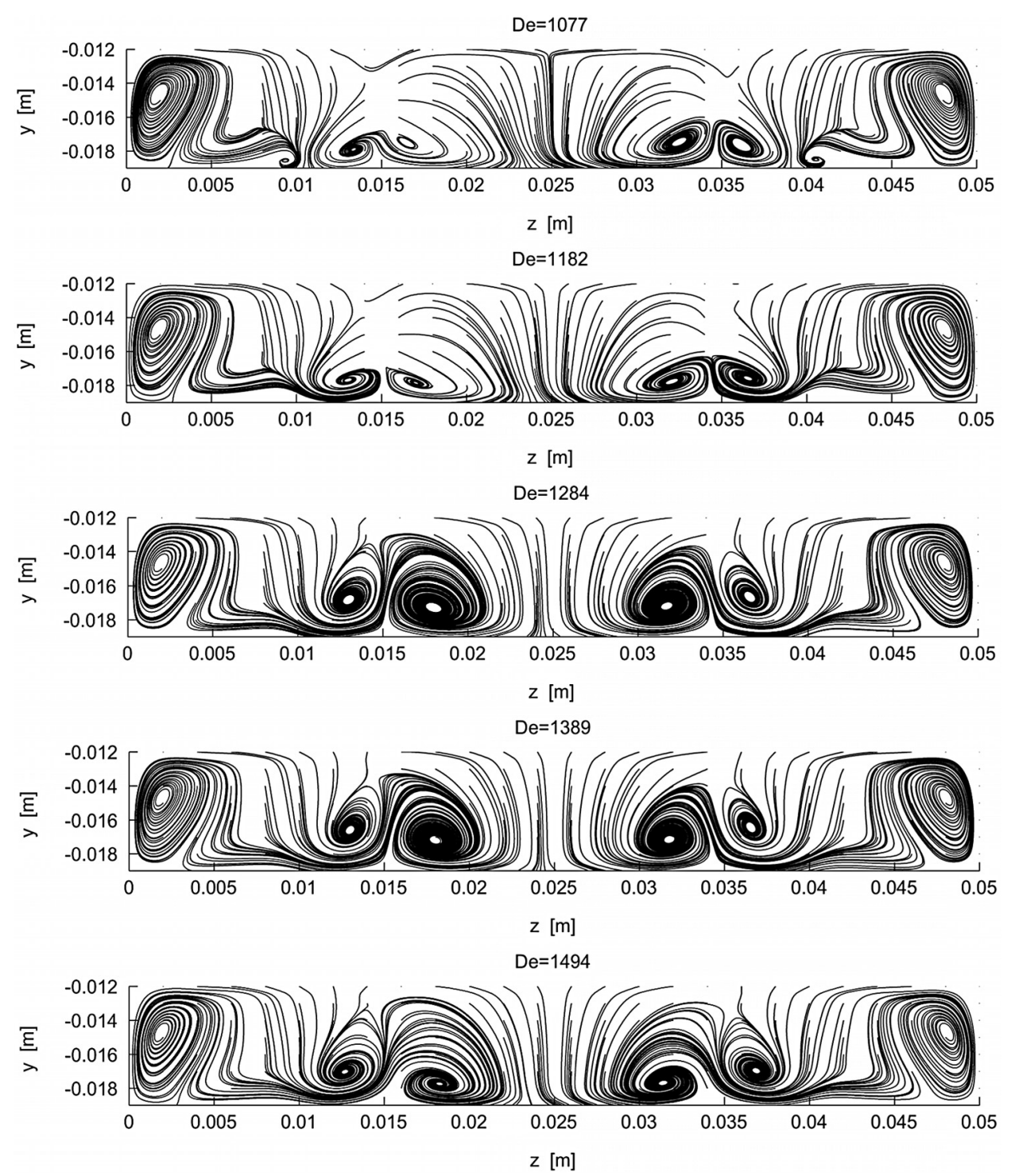

Figure 7. Flow pattern in the middle of the duct for $1,077 \leq \mathrm{De} \leq 1,494$.

function of Dean number. The Nusselt number for a straight rectangular duct, based on Shah and London's work [30], is also presented. Heat transfer coefficient in the curved duct increases with Dean number, while in a straight duct the Nusselt number is constant. The maximum Nusselt number for a curved duct is 10 times higher than that of a straight duct. This heat transfer enhancement is attributed to two mechanisms. First, the secondary flow induced by centrifugal forces due to the curvature of the duct leads to the appearance of secondary vortices. Second, the flow in a straight duct, oppositely to a curved duct, is assumed to be thermally fully developed. It is 

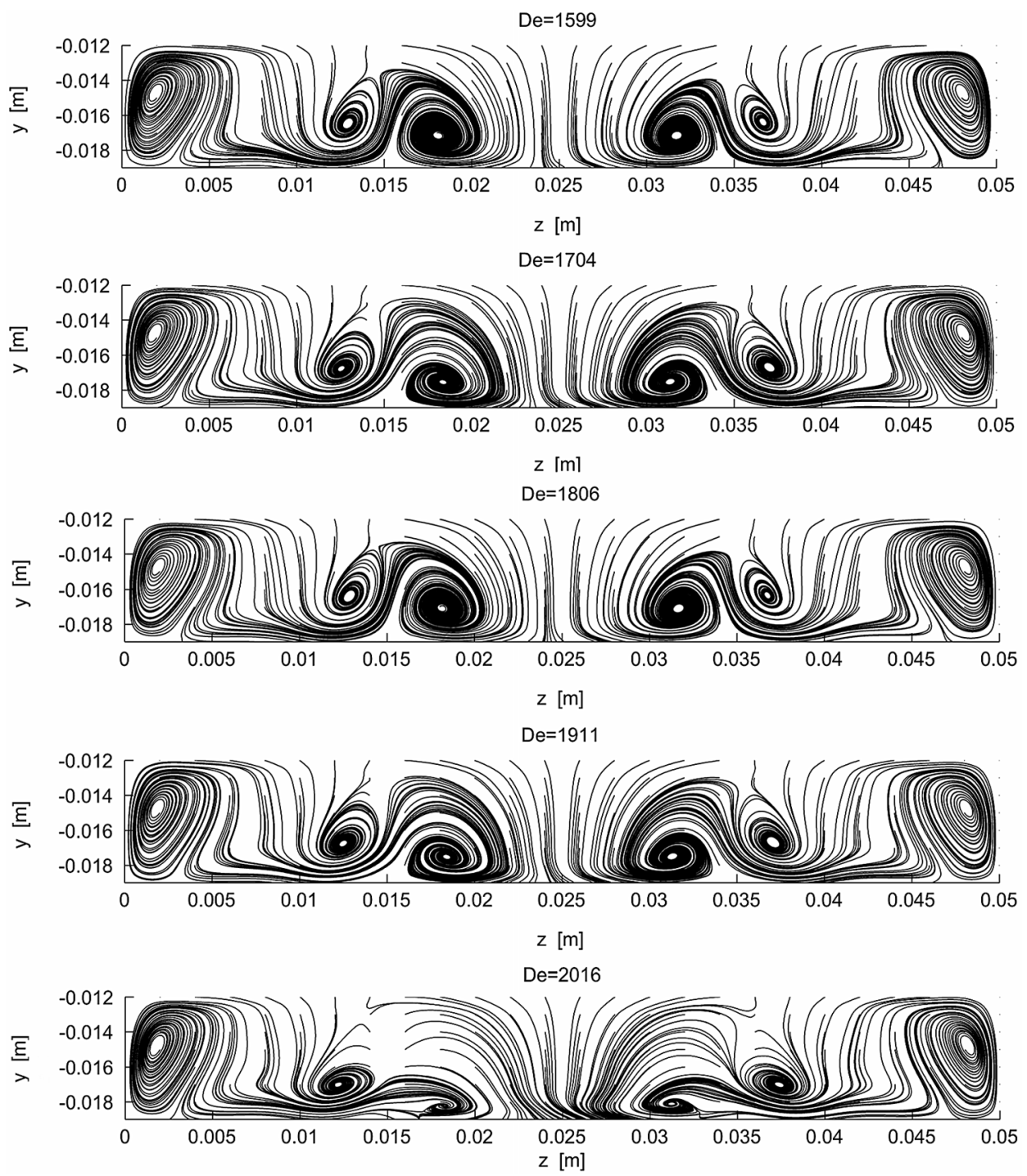

Figure 8. Flow pattern in the middle of the duct for $1,599 \leq \mathrm{De} \leq 2,016$.

well understood that in the thermal entrance region the heat transfer coefficient is augmented.

The next figures (Figures 5-8) show the secondary flow streamlines for several Dean numbers in a section perpendicular to the main flow direction, in the middle of the duct. The flow pattern is characterized by three pairs of vortices for a Dean number larger than 131. For small Dean numbers $(<131)$ there is only one pair of vortices. Winters [10] had concluded that a transition from one pair of vortices to two pairs of vortices happens for a Dean number between 113 and 191. Above 
$\mathrm{De}=1,000$, the vortices increase in size, increasing flow disturbance. The patterns are similar for De $>1,200$.

The variation of Nusselt number in Figure 4 is in agreement with the flow patterns presented. There is a sharp increase in Nusselt number for a Dean number of about 1,000. Above that, the contours of streamlines are similar and consequently the variation in Nusselt number is small - an almost constant value of 38-39 was observed. A good correlation was obtained between Nusselt number and Dean number, valid for Dean number up to 1,000 :

$$
\mathrm{Nu}=0.8508 \mathrm{De}^{0.5207}
$$

By comparing the results with those of Chandratilleke and Nursubyakto [16], we can conclude that the heat transfer coefficient is higher for heat transfer on the convex wall only, compared to heat transfer on the concave wall only. This was also verified by applying the present model to the concave wall heating situation (convex wall insulated). Note that other researchers found a higher coefficient on the concave wall, for simultaneous heat transfer in both walls, although for a square duct [13] and with a much larger aspect ratio [14].

\section{CONCLUSIONS}

Laminar-convection heat transfer in a rectangular curved duct, with an aspect ratio of 7.14 , has been investigated numerically with a computational fluid dynamics code. The duct is heated in the convex surface with the other walls insulated.

A numerical correlation for the Nusselt number was obtained and compared with heat transfer in a straight duct. The results showed a Nusselt number up to 10 times higher. This is explained by the appearance of secondary vortices and eventually the enhancement caused by the thermal entrance region.

The contours of secondary flow streamlines are similar for a Dean number larger than 1,200. The flow pattern changed from one pair of vortices to three pairs of vortices for a Dean number of 131 .

It was concluded that the heat transfer coefficient is higher for heat transfer on the convex wall only, compared to heat transfer in the concave wall only.

\section{REFERENCES}

1. J. Facão and A. C. Oliveira, Simulation of the Thermal Behaviour of a Hybrid Heat Pipe Solar Collector, Proc. SET2002 Conf. (1st Int. Conf. on Sustainable Energy Technologies), Popdesign, Porto: Portugal, 2002.

2. J. Facão, S. Varga, and A. C. Oliveira, Evaluation of the Use of Artificial Neural Networks for the Simulation of Hybrid Solar Collectors, Int. J. Green Energy, vol. 1, no. 3, pp. 337-352, Marcel Dekker, 2004.

3. Thermo Technologies, Thermomax Solar Collectors, www.thermomax.com.

4. W. R. Dean, Note on the Motion of Fluid in a Curved Pipe, Phil. Mag., vol. 4, pp. 208-223, 1927.

5. W. R. Dean, The Stream-Line Motion of Fluid in a Curved Pipe, Phil. Mag., vol. 5, pp. 673-695, 1928. 
6. Y. Mori, Y. Uchida, and T. Ukon, Forced Convective Heat Transfer in Curved Square Channel with a Square Cross Section, Int. J. Heat Mass Transfer, vol. 14, pp. 1787-1805, 1970.

7. K. C. Cheng and M. Akiyama, Laminar Forced Convection Heat Transfer in Curved Rectangular Channels, Int. J. Heat Mass Transfer, vol. 13, pp. 471-490, 1970.

8. R. Chilukuri and J. A. C. Humphrey, Numerical Computations of Buoyancy-Induced Recirculation in Curved Square Duct Laminar Flow, Int. J. Heat Mass Transfer, vol. 24, pp. 305-314, 1981.

9. G. J. Hwang and C.-H. Chao, Forced Laminar Convection in a Curved Isothermal Square Duct, Trans. ASME, J. Heat Transfer, vol. 113, pp. 48-55, 1991.

10. K. H. Winters, A Bifurcation Study of Laminar Flow in a Curved Tube of Rectangular Cross-Section, J. Fluid Mech., vol. 180, pp. 343-369, 1987.

11. H. Bippes and H. Görtler, Dreidimensionale Störungen in der Grenzschicht an Einer Konkaven Wand, Acta Mech., vol. 14, pp. 251-267, 1972.

12. A. Philip, J. Mees, K. Nandakumar, and J. H. Masliyah, Instability and Transitions of Flow in a Curved Square Duct: The Development of Two Pairs of Dean Vortices, J. Fluid Mech., vol. 314, pp. 227-246, 1996.

13. J. H. Chung and J. M. Hyun, Convective Heat Transfer in the Developing Flow Region of a Square Duct with Strong Curvature, Int. J. Heat Mass Transfer, vol. 35, no. 10, pp. 2537-2550, 1992.

14. P. M. Ligrani, S. Choi, A. R. Schallert, and P. Skogerboe, Effects of Dean Vortex Pairs on Surface Heat Transfer in Curved Channel Flow, Int. J. Heat Mass Transfer, vol. 39, no. 1, pp. 27-37, 1996.

15. P. M. Ligrani and C. R. Hedlund, Transition to Turbulent Flow in Curved and Straight Channels with Heat Transfer at High Dean Numbers, Int. J. Heat Mass Transfer, vol. 41, pp. 1739-1748, 1998.

16. T. T. Chandratilleke and Nursubyakto, Numerical Prediction of Secondary Flow and Convective Heat Transfer in Externally Heated Curved Rectangular Ducts, Int. J. Thermal Sci., vol. 42, pp. 187-198, 2003.

17. B. Zhang, C. X. Lin, and M. A. Ebadian, Combined Turbulent Forced Convection and Thermal Radiation in a Curved Pipe with Uniform Wall Temperature, Numer. Heat Transfer A, vol. 44, pp. 149-167, 2003.

18. Z. F. Dong and M. A. Ebadian, Thermal Developing Flow in a Curved Duct with an Elliptic Cross Section, Numer. Heat Transfer A, vol. 24, pp. 197-212, 1993.

19. Z. F. Dong and M. A. Ebadian, Effects of Buoyancy on Laminar Flow in Curved Elliptic Ducts, Trans. ASME, J. Heat Transfer, vol. 114, pp. 936-943, 1992.

20. J. C. Sturgis and I. Mudawar, Assessment of CHF Enhancement Mechanisms in a Curved Rectangular Channel Subjected to Concave Heating, Trans. ASME, J. Heat Transfer, vol. 121, pp. 394-404, 1999.

21. J. C. Sturgis and I. Mudawar, Critical Heat Flux in a Long Curved Channel Subjected to Concave Heating, Int. J. Heat Mass Transfer, vol. 42, pp. 3831-3848, 1999.

22. L. Wang and T. Yang, Bifurcation and Stability of Forced Convection in Curved Ducts of Square Cross-Section, Int. J. Heat Mass Transfer, vol. 47, pp. 2971-2987, 2004.

23. T. W. Gyves and T. F. Irvine, Jr., Laminar Conjugated Forced Convection Heat Transfer in Curved Rectangular Channels, Int. J. Heat Mass Transfer, vol. 43, pp. 3953-3964, 2000.

24. T. W. Gyves, T. F. Irvine, Jr., and M. H. N. Naraghi, Gravitational and Centrifugal Buoyancy Effects in Curved Square Channels with Conjugated Boundary Conditions, Int. J. Heat Mass Transfer, vol. 42, pp. 2015-2029, 1999. 
25. C. R. Andrade and E. L. Zaparoli, Effects of Temperature-Dependent Viscosity on Fully Developed Laminar Forced Convection in a Curved Duct, Int. Commun. Heat Mass Transfer, vol. 28, pp. 211-220, 2001.

26. V. Velidandla, S. Putta, and R. P. Roy, LDV Measurement of Turbulent Liquid Velocity Field in Channels with Curved Wall, Int. Commun. Heat Mass Transfer, vol. 21, pp. 765-773, 1994.

27. Fluent, Inc., FLUENT 6.0 User's Guide, 2001.

28. H. K. Versteeg and W. Malalasekera, An Introduction to Computational Fluid Dynamics: The Finite Volume Method, Prentice Hall, 1995.

29. S. V. Patankar and D. B. Spalding, A Calculation Procedure for Heat, Mass and Momentum Transfer in Three-Dimensional Parabolic Flows, Int. J. Heat Mass Transfer, vol. 15, pp. 1787-1806, 1972.

30. R. K. Shah and A. L. London, Laminar Flow Forced Convection in Ducts, Supplement 1 to Advances in Heat Transfer, in T. F. Irvine and J. P. Hartnett, (eds.), Academic Press, New York, 1978. 